\title{
Special Issue on Recent Developments in Bioinspired Algorithms
}

\author{
L. Jourdan · E.-G. Talbi
}

Published online: 11 February 2010

(C) Springer Science+Business Media B.V. 2010

Bioinsipired algorithms have been deigned using paradigms issued of nature such as evolution, food foraging, etc. Recently, some new algorithms have appeared as particle swarm, honey bees algorithms. The main goal of this special issue is to report the recent development of bioinspired algorithms in order to provide a recent snapshot for the community. This special issue of the Journal of Mathematical Modelling and Algorithms (JMMA) contains selected articles presented at the META'08 conference held in November 2-4, 2006, in Hammamet, Tunisia. The articles are original research papers that describe bioinspired algorithms to solve both academic problems (assignment problem, co-clustering) and real life applications (protein structure prediction, molecular docking).

The first paper by C-E. Bichot addresses a problem of word document coclustering which is solved thanks a fission-fusion algorithm. The author provides a comparison of results with several other algorithms and shows the performance of his approach.

In the second paper of the special issue, C. Adiche and M. Ayder propose a hybrid method to solve a multi-objective assignment problem. The authors present a cooperative algorithm combining a multi-objective simulated annealing (MOSA) and a branch-and-bound method.

The paper by D. Boughaci, B. Benhamou and H. Drias present local search methods for the optimal winner determination problem in combinatorial auctions.

In the next paper of the special issue, R. Fonseca, M. Paluszewski and P. Winter present the application of the so-called Bee Colony Optimization (BCO) method to generate sub-optimal solutions to the protein structure prediction problem. A comparison of quality of $\mathrm{BCO}$ with different approaches is provided.

L. Jourdan $(\varangle) \cdot$ E.-G. Talbi

INRIA Lille Nord Europe, LIFL, University of Lille, Lille, France

e-mail: laetitia.jourdan@inria.fr

E.-G. Talbi

e-mail: el-ghazali.talbi@lifl.fr 
Finally, the last paper of the issue by J-C. Boisson, L. Jourdan, E-G. Talbi and D. Horvath solves the flexible docking problem which is an essential problem in drug design. The authors focus on the impact of the hybridization in multi-objective optimization to solve the problem. The performances are assessed by numerical experiments.

We thank our referees for their efforts, time and valuable criticism and suggestions as well as Vic Rayward-Smith for giving us the opportunity to edit this special issue. 